\title{
Valuation Methodology of Information Technology (IT) Value in the IT-based Business \\ A Case Study at a Leading Telecommunication Company
}

\author{
Lukman Abdurrahman ${ }^{1,2}$, Suhardi ${ }^{1}$, and Armein Z.R. Langi ${ }^{1}$ \\ ${ }^{1}$ School of Electrical Engineering and Informatics, Institut Teknologi Bandung, \\ Jl. Ganesha 10, Bandung 40132, Indonesia \\ ${ }^{2}$ Information Systems Program, Industrial Engineering Faculty, Telkom University, \\ Jl. Terusan Buah Batu, Bandung 40257, Indonesia
}

\begin{abstract}
This study aims to propose measuring the IT value, which is still in a lengthy discussion because concrete solutions have not existed to explicate it. Therefore, this study tries to present a sequence of methods to assess this value through both qualitative and quantitative methods. The presented methodology addresses the IT valuation by means of the IT value definition approach as a result of the division between the IT functions and the IT costs, which is achieved by analyzing functions and costs previously, consecutively, results in the intrinsic IT value. Additionally, this value at that point works together with the business environment, i.e. the Business Model Canvas so it brings up a new added value entitled an extrinsic IT value. Thus, the entire IT value manifests as the product of these two values. Furthermore, Telkom data appear to examine this valuation methodology, where the results show that an alignment appears between the presented valuation methodology and the case study, although it still needs a number of improvements. Based on this valuation methodology, the IT value engineering concept can be optimistic to continue research at the subsequent time.
\end{abstract}

Keywords: valuation, IT value, methodology, business environment, intrinsic value, extrinsic value.

\section{Introduction}

Business organizations have massively depended on information technology (IT) as a business enabler and transformer. Accordingly, IT has become an interesting object to study, especially to argue against an IT productivity paradox topic in research fields to quantify its value compared with its investment. Meanwhile, in practice, IT has delivered numerous advantages to the organization such that almost no commercial organizations without involving IT in its operations. This perspective is consistent with the fact that worldwide IT spending always grows over time as shown by the Gartner survey [8].

This paper aims to study a valuation methodology to estimate the IT value, which originates from the IT utilization within a business organization as a combination of assets, capabilities, environment interactions so that results in a productive use of IT [7]. Also, this relates to that IT does not create business values in an isolated environment, but needs combining with other internal organizational factors [6]. Thus, the IT value comprises a variety point of views from internal and external factors, in which IT has been a strategic factor of the organization [6], [20].

Therefore, this study tries investigating a solution to estimate the IT value resulted from both the IT inclusion as an intrinsic value and the IT environment as an extrinsic value. Moreover, both the intrinsic and the extrinsic values work together to produce the IT value, which manifests in a currency or other forms. For that reason, the intrinsic value is derived from the value implied in the IT as a result of a division of the IT function by its cost. Meanwhile, the extrinsic value is a consequence of organization of the intrinsic IT value managed in the business environment. Likewise, if the intrinsic IT value is properly aligned with the business organization, the resulted value can be extraordinary because it is a

Received: September $5^{\text {th }}, 2014$. Accepted: November $26^{\text {th }}, 2016$ 
multiplication of the intrinsic and the extrinsic values. On the contrary, if the alignment of IT and the business is corrupt, the entire values can be corrupt as well. In essence, this methodology rests on the value engineering methodologies [9].

Furthermore, this study applies the methodology to a case study conducted at PT. Telkomunikasi Indonesia, Tbk. (Telkom) as the largest and leading Information and Communication Technology (ICT) provider in Indonesia. The functions of Telkom's IT services are based on eTOM (enhanced Telecom Operation Map) business process framework [25],[30]. The result shows that the value of IT within the organization has significant roles, both the intrinsic and the extrinsic values are intertwined, also, depending upon tune of the top and the corporate culture.

Correspondingly, this paper is a follow-up study of previous studies which have been carried out by [1] and [2], which focused on IT value engineering studies. Additionally, those papers had related to previous papers proposed by [13][21] and [21] addressing the relationship between IT and business performance. Particularly, this paper is a revised and expanded version of a paper as in [3] and an attempt implementation of the ideas written on [9]. On the contrary, this paper is outside of past studies such as Strassmann (1997) who argued that there was no apparent relationship between IT spending and any measures of organization profitabilities, such as return on asset, return on equity, and economic value added [4].

Furthermore, the principal contributions of this study are subsequent:

1) This study essentially adopts the methodology based on [9], however, this methodology is only partly to measure the intrinsic IT value. Furthermore, the extrinsic IT valuation methodology employs methods developed by an ontology approach, see the Equations (15) to (19), and borrow the Business Model Canvas's logic [15], [16] to be adopted as the IT business context. In other words, the study offers a comprehensive IT valuation methodology as a major contribution, from inner and outer point of views (see Figure 2).

2) This study proposes a value engineering-based methodology, which has not been used in previous studies to measure the IT value at least on the references of this study. For example, methods of research [13], [14], and [21] have used a statistical approach, such the structural equation modeling, for a quantitative matter.

3) This study results in the valuation methodology of IT value, which is not only to refashion the patterns of relationships between the IT cost and the firm performance in a different way but also to result in the concrete calculation of the IT cost and the firm performance. This is in contrast to the study conducted by [21], which outlined how the testing IT resources and capabilities affect firm performance. Similarly, in a study of [13] and [14], which put more emphasis on testing whether information technology and organizational resources have a significant effect on firm performance.

The remainder of the paper presents the topic as follows. Section two addresses literature reviews, discussing the value definition, IT value creation and its model, which refers to the Resource-Based View, the value engineering, and the Business Model Canvas. Section three discusses a research methodology that bases this study. Section four is a case study performed for PT. Telekomunikasi Indonesia, Tbk. (Telkom). Section five is a discussion and a recommendation. The last is section six, which is concluding all.

\section{Literature Review}

\section{A. Value Definition}

A value refers to usefulness, worth, benefit, etc., which reveals if the interaction among two or more systems or subsystems occurs. A system works on the other one and vice versa, or the system works at the instigation of other systems. Why the systems would mutually operate. It occurs due to a force that drives the systems to work, in which the force reveals as a usefulness, a worth, a benefit, and the like. In other words, this understanding helps to accomplish the stage of a value creation by benefiting system processes. 
Consequently, there are various types of values such as normative value, realist value, and perceived value. The normative value is related to required value as planned previously, the realist value pertains to ensued value obtained from an accomplishment, and the perceived value is what consumer relatively perceives [14]. If seen from cost management viewpoints, the other types of values are the use value, i.e. the value of required function associated with the cost. Afterward, the cost value, i.e. the all cost values dedicated to result in the item; the esteem value, i.e. the value of additional costs to pay the additional items as well; and the exchange value, i.e. the value of an item to change something else [28], [29].

As a fundamental nature of a value definition of this study, the definition in the Equation (1) is a basic concept to engineering the value. This equation technically formulates a value $(\mathrm{V})$ as an expression of a division of function (F) by cost (C) as proposed by [10] as follows:

$$
V=\frac{F}{C}
$$

According to the formula, several efforts to bring the value up are:

- For the same function $(\mathrm{F})$, reduce the cost $(\mathrm{C})$ or

- The cost $(\mathrm{C})$ is constant, increase the function $(\mathrm{F})$ or

- $\quad$ The function (F) slightly reduced, the cost $(\mathrm{C})$ significantly decreased or

- $\quad$ The cost (C) a slight increase, the function (F) has increased significantly or

- $\quad$ The function $(\mathrm{F})$ increases while the cost $(\mathrm{C})$ decreases.

\section{B. IT Value Creation}

In order to optimally produce values, IT systems should perform to support the business processes, which represent system functions to operate the business and deliver advantages to the stakeholders, such as customers and shareholders. Meanwhile, these functions describe cost centers of infrastructures, which should run these business processes. Obviously, the infrastructures consist of the IT infrastructure, although its capacity depends on types of organizations. In other words, this reason relates to the Equation (1) above, whereas a value is equivalent to a division of functions by costs. Accordingly, the IT value creation can occur if the value itself is worth for the stakeholders to invest the infrastructures in operating the organization functions.

Moreover, the IT value can result from a complex system that consists of various subsystems, components, subcomponents, and parts. Several subsystems may be a moment in time, shareholders, individual attributes, assignment impacts, external relationships, and management. As measuring the IT value, it is important to think about measurements that should concentrate on [27]. Likewise, performing the IT valuation involves complex issues including social accomplishment so it requires over a period of time. Thus, the IT infrastructures and the organizational factors should operate in a synergistic fashion, in which these factors are parts of the IT-based system as well. The IT-based system, as well as the organization, contains IT and non-IT human resources, IT management skills, procedures and policies, information benefits, affiliation benefits, way of life, and rules.

\section{IT Value Creation Model: Resource-Based View}

Liang et al. (2010) stated that resource-based view (RBV) theory is the major theory adopted to comprehend the relationship between IT and firm performance. The theory was firstly proposed by Wernerfelt (1984), who argued that to achieve a competitive advantage, a firm has to possess valuable and rare resources [13]. Meanwhile, Barney (1991) categorized resources as physical capital, human capital and organizational capital [7]. Further, Barney characterized resources as strategically significant to pursue firm's competitive advantages if they are: valuable, means that the firm is able to develop and implement strategies towards increasing efficiency and effectiveness; rare, indicates that resource usage could lead the firm to own a great different advantage; inimitable, suggests that the resource is unique, so that 
competitors cannot obtain it due to imperfectly imitable; and non-substitutable, no other resources can replace the original resource [17].

Moreover, valuable IT resources are consecutively able to provide a firm with their capability to sustain a competitive advantage. Therefore, Ravichandran and Lertwongsatien (2005) argued that between firm's IT resources and capabilities own constructive relationships [12], so it leads to comprehending the IT capability, which exists as "the ability to mobilize and deploy IT-based resources in combination or co-present with other resources and capabilities" [4] on one hand. On the other hand, Bharadwaj (2000) mentioned that a firm's IT capability draws from fundamental strengths in IT infrastructure, human IT resources, and IT-enabled intangibles. The IT infrastructure helps the firm launch innovative applications faster than the competitor does. While the human IT resources play to conceive of and implement such applications faster than the competitor implements. Likewise, the IT-enabled intangibles allow the firm to leverage pre-existing organizational intangibles, such as customer orientation and synergy within the firm [4].

\section{IT Value Engineering}

As mentioned above, the IT value contains a variety of viewpoints, whereas between academics and practitioners, as well as between IT managers and IT professionals, have different comprehensions [23][27]. The researchers and practitioners believe that the IT role has matured in driving operational and strategic business to improve sustainable competitive advantages. While IT managers and professionals concentrate on providing infrastructure for informing to include not only work processes but the group dynamics issues of collaboration so that IT can ultimately develop value technology.

Meanwhile, engineering semantically pertains to an engine paradigm to solve a problem. In practice, an engine moves in a self-perpetuating condition resulted from locking readily available forces against each other in a stable cyclic (closed-loop) fashion [11]. Furthermore, about a value engineering concept, Tohidi (2011) stated that its idea is to employ the project, augment accomplishment, and diminish costs in all life cycles of the project. In this case, the lifetime value of engineering project with the productivity increment can join to result in the project value, i.e. the output is divided by input. Hence, the implementation of the value engineering is boiling down on the performance improvement [26]. Additionally, he mentioned that the value engineering is constantly dealing with the growth of technology, reducing the unnecessary costs that do not relate to improving the quality of products or services. On the contrary, in the value engineering, the usage of knowledge, the recognition of problems, the methodology of problem solving, the development of creative solutions could combine with comprehensive approaches [26].

Furthermore, Sharma (2012) added that the value engineering is a structured method to investigate the function of systems and its completeness in dealing with the accomplishment of systems fundamental functions at the lowest cost. However, on the other hand, the functions of systems consistently keep up a better performance, trustworthiness, quality, and security [24]. In other words, the value engineering is a structured study of functions to assure the user's needs with a quality outcome at the lowest life cycle cost by means of applying creativities. Accordingly, the value engineering helps organizations compete extra effectively by decreasing costs, increasing profits, improving quality, solving problems, saving time, using resources more effectively, etc.

In terms of the IT value, the IT generally boils down to effectiveness and efficiency of processes, including achieving the best organization performance. Thus, IT should disseminate value-added advantages through a strategic alignment with the whole organizations. Hence, the IT value engineering is a structured study of the IT functions to deliver advantageous business performance at the lowest costs by means of engineering IT and business parameters within a business environment. 


\section{E. Business Model Canvas: IT Value Engineering Environment}

Using an ontological approach, Osterwalder (2004) defined a business model as "a conceptual tool that contains a set of elements and their relationships and allows expressing a company's logic of earning money. It is a description of the value a company offers to one or several segments of customers and the architecture of the firm and its network of partners for creating, marketing and delivering this value and relationship capital, in order to generate profitably and sustainable revenue streams" [15].

In order to explore for further research, the IT value conceptual model should work together with a business model, which describes what an organization does and how it can make money [5]. However, in this study, the business model is a means where the IT value conceptual model can work with. For that reason, to deal with the business model, the business model canvas (BMC) turns out to be an IT value engineering environment because it describes, challenges, designs, and invents business models more systematically. In addition, there are nine building blocks making up the model; namely customer segments, value propositions, channels, customer relationships, revenue streams, key resources, key activities, key partners, and cost structures [15].

The explanation of each block is as follows:

1. Customer Segments define groups of people or organizations, where the business aims to reach and serve. The customer segments are those who have needs to justify a distinct offering through different distribution channels, require different types of relationships, have different levels of profitability, and interest in a subset of the value proposition.

2. Value Propositions describe bundles of products or services that create value for a specific customer segment, value delivered to the customer (benefit/cost), customer problem being solved, customer needs being satisfied, and value propositions assigned to customer segments.

3. Channels describe how a firm communicates with and reaches its customer segments to deliver a value proposition. Their functions are raising awareness among customers about firm's products and services, helping customers evaluate a firm's value proposition, allowing customers to purchase specific products and services, delivering a value proposition to customers, and providing post-purchase customer support.

4. Customer Relationships describe the types of relationships a firm establishes with specific customer segments. This is necessary to perform in terms of customer acquisitions, customer retentions, and boosting sales (upselling), in which their contact could be personal or automated.

5. Revenue Streams are the cash a firm generates from each customer segment and represents the customer segment's quantification of the value proposition.

6. Key Resources describe the most important assets required to make a business model work and allow an enterprise to create and offer a value proposition, reach markets, maintain relationships with customer segments and earn revenues.

7. Key Activities describe the most imperative things a firm must do to make sure its business model work.

8. Key Partners describe the network of suppliers and partners that make sure the business model works to obtain an optimization and an economy of scale, reduction of risk and uncertainty, and acquisition of particular resources and activities.

9. Cost Structure describes all costs incurred to operate a business model, cost-driven business models focus on minimizing costs whenever possible, and value-driven business models are less concerned about cost, focusing instead on value creation [5], [15], [16].

\section{Research Methodology}

A. Research Scheme

In order to achieve the purpose of this research, the scheme of research roadmap is as follows on Figure 1: 


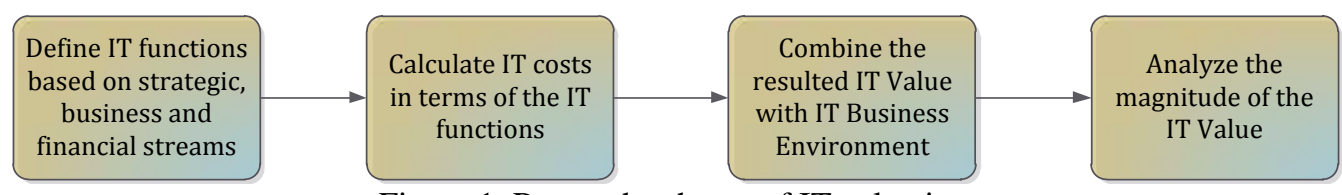

Figure 1. Research scheme of IT valuation

As a continuation of the past researchers, this study starts up from the IT value definition, which stems from the Equation (1) that the value is a division of IT functions by its costs. Furthermore, the IT functions consist of the following three categories: strategic, business, and financial streams [22]. In addition, the IT value also comes from IT resources that completely have the capability to improve the performance of the organization [21]. Moreover, the IT value should come together with the business environment, which the total IT value ultimately reveals as a joint value of the complete business.

\section{B. IT Value Function}

Based on the research scheme above, the IT valuation originates from the IT functions containing the following three streams [22]:

- Strategic streams, whereas the IT spending has tight alignments to the business organization to strategically improve the organizational performance. In other words, the streams relate to the high-level business processes.

- Business streams, which are the result of the resource allocation and execution to the business processes within the organization. Therefore, IT is a basis to retain and raise the organizational performance indirectly by enabling the business operations.

- Financial streams, which directly depict the organizational performance reflecting the invested IT spending to the organization.

\section{Determination of IT Functions}

Table 1. List of functions of IT

\begin{tabular}{|c|c|c|}
\hline \multirow{3}{*}{ Streams of IT Function } & \multicolumn{2}{|c|}{ Levels of Functions } \\
\hline \multirow{3}{*}{ Strategic } & Fundamental & $\mathrm{f}_{1}, \ldots \mathrm{f}_{\mathrm{a}}$ \\
\cline { 2 - 3 } & Enhanced & $\mathrm{f}_{(\mathrm{a}+1)}, \ldots \mathrm{f}_{\mathrm{b}}$ \\
\cline { 2 - 3 } & Superior & $\mathrm{f}_{(\mathrm{b}+1)}, \ldots \mathrm{f}_{\mathrm{c}}$ \\
\hline \multirow{3}{*}{ Business } & Fundamental & $\mathrm{f}_{1}, \ldots \mathrm{f}_{\mathrm{d}}$ \\
\cline { 2 - 3 } & Enhanced & $\mathrm{f}_{(\mathrm{d}+1)}, \ldots \mathrm{f}_{\mathrm{e}}$ \\
\cline { 2 - 3 } & Superior & $\mathrm{f}_{(\mathrm{e}+1)}, \ldots \mathrm{f}_{\mathrm{g}}$ \\
\hline \multirow{5}{*}{ Financial } & Fundamental & $\mathrm{f}_{1}, \ldots \mathrm{f}_{\mathrm{h}}$ \\
\cline { 2 - 3 } & Enhanced & $\mathrm{f}_{(\mathrm{h}+1)}, \ldots \mathrm{f}_{\mathrm{k}}$ \\
\cline { 2 - 3 } & Superior & $\mathrm{f}_{(\mathrm{k}+1)}, \ldots \mathrm{f}_{\mathrm{m}}$ \\
\hline
\end{tabular}

In order to verify the IT functions, previously it appears as seen in Table 1 , whereas $\mathrm{f}_{1}, \ldots$, $f_{a}$, etc. are samples of the detailed functions [9]. Hence, as mentioned above, the IT functions consist of three streams: strategic, business, and financial streams. Furthermore, each stream has three levels of functions: fundamental functions describing the basic functions that must be owned by each stream as essential functions; enhanced functions are the improvement of the 
fundamental ones; and the superior functions are advanced IT roles, which contribute the highest values to the business. Additionally, each level has detailed functions, which have the serial number of the appropriate number of functions. For example, according to Table 1, the fundamental functions of the strategic stream have $a$ detailed functions, i.e. $f_{1}$ to $f_{a}$. The enhanced functions have $(b-a)$ detailed functions, i.e. $\mathrm{f}_{(\mathrm{a}+1)}$ to $\mathrm{f}_{\mathrm{b}}$. Likewise, the superior functions have $(c-b)$ detailed functions, i.e. $\mathrm{f}_{(\mathrm{b}+1)}$ to $\mathrm{f}_{\mathrm{c}}$. So do the streams of business and finance, in which this function analysis results in an index unit of the function parameter.

In addition, the serial number is just as sequencing to determine the estimation priority. In this case, the priority order starts from the strategic to the financial stream. Similarly, the order level starts from the fundamental then ends on the superior level.

In order to measure the IT functions in a quantification fashion, it conducts through such steps [9]:

1. Determine the index of the Scale of Strategy (SS), the Scale of Business (SB), and the Scale of Finance (SF).

2. Calculate these indexes based on an arithmetic manipulation as follows:

As $\quad i=$ indicates the $i$ th of analyzed functions

$f_{i}=\left\{\begin{array}{l}1, \text { if function } i \text { is ready to operate } \\ 0, \text { if not }\end{array}\right.$

$p_{i}=\left\{\begin{array}{l}1, \text { for fundamenta } 1 \text { th functions of each stream } \\ 2, \text { for enhanced } i \text { th functions of each stream } \\ 3, \text { for superior } i \text { th functions of each stream }\end{array}\right.$

$M F=$ Maximum Function score of each stream that should be ideally available within each stream, there is a formula to count it below.

$N=$ real number

Accordingly, to formulate the index of the Scale of Strategy (SS) (see Table 1) is as follows:

$$
\begin{aligned}
p_{i}=\left\{\begin{array}{l}
1, \text { if } 1 \leq i \leq a \\
2, \text { if }(a+1)<i \leq b, i \in N \\
3, \text { if }(b+1)<i \leq c
\end{array}\right. \\
M F=\sum_{i=1}^{c} P i \\
S S=\frac{\sum_{i=1}^{c} p_{i} f_{i}}{M F}
\end{aligned}
$$

With the similar step, the index of the Scale of Business (SB) manifests as follows (see Table 1):

$$
\begin{aligned}
p_{i} & =\left\{\begin{array}{l}
1, \text { if } 1 \leq i \leq d \\
2, \text { if }(d+1)<i \leq e, i \in N \\
3, \text { if }(e+1)<i \leq g
\end{array}\right. \\
M F & =\sum_{i=1}^{g} P i
\end{aligned}
$$




$$
S B=\frac{\sum_{i=1}^{g} p_{i} f_{i}}{M F}
$$

Likewise, the index of the Scale of Finance (SF) is in this manner (see Table 1):

$$
\begin{aligned}
& p_{i}=\left\{\begin{array}{l}
1, \text { if } 1 \leq i \leq h \\
2, \text { if }(h+1)<i \leq k, i \in N \\
3, \text { if }(k+1)<i \leq m
\end{array}\right. \\
& M F=\sum_{i=1}^{m} P i \\
& S F=\frac{\sum_{i=1}^{m} p_{i} f_{i}}{M F}
\end{aligned}
$$

Furthermore, the Function Parameter (F) is an average of the scales of strategic, business, and financial streams. In here [9] suggests adding a performance effectiveness factor $\left(\mathrm{e}_{\mathrm{j}}\right)$ as correction factors to each scale of the stream. Thus, the $F$ and $e_{j}$ can appear as seen in Equations (11) and (12) below:

$$
\begin{aligned}
F= & \frac{\left(S S^{*} e 1\right)+\left(S B^{*} e 2\right)+\left(S F^{*} e 3\right)}{3} \\
e_{j} & =\frac{\left[\frac{\text { worked functions }}{\text { total functions }}\right] \text { fundamental }+\left[\frac{\text { worked functions }}{\text { total functions }}\right] \text { enhanced }+\left[\frac{\text { worked functions }}{\text { total functions }}\right] \text { superior }}{3}
\end{aligned}
$$

Where as $\mathrm{e}_{\mathrm{j}}=$ the performance effectiveness factor of the $j^{\text {th }}(\mathrm{j}=1$ to 3 in this study) stream of functions. This factor performs based on completeness of the IT functions of each stream in the implementation in the field. It means that the more complete functions in the implementation, the more effective the performance of the functions, therefore, the F looks as an index unit.

\section{IT Cost Calculation}

Table 2. Cost parameter components

\begin{tabular}{|l|l|}
\hline \multicolumn{1}{|c|}{ Cost Category } & \multicolumn{1}{|c|}{ Cost Components } \\
\hline \multirow{4}{*}{ 1. Capital Expenditure $(\mathrm{CE})$} & $\mathrm{CE}_{1}$ \\
\cline { 2 - 2 } & $\ldots \ldots$ \\
\cline { 2 - 2 } & $\mathrm{CE}_{\mathrm{n}}$ \\
\hline \multirow{3}{*}{ 2. Operational Expenditure $(\mathrm{OE})$} & $\mathrm{OE}_{1}$ \\
\cline { 2 - 2 } & $\ldots \ldots$ \\
\cline { 2 - 2 } & $\mathrm{OE}_{\mathrm{m}}$ \\
\hline
\end{tabular}

In order to assess the IT costs, the Life-Cycle Cost Analysis (LCCA) technique provides us with the comprehensive calculation of costs. The LCCA is an elemental outline process in terms of the scheming of the preliminary and the forthcoming cost of a project. The LCCA is useful to estimate at any kind of the project scheme as an effective tool to assess the capital and operational expenditure [19]. Therefore, to assess the IT cost firstly is to classify the cost sources into two large categories: capital and operational expenditure. Moreover, each 
category should be broken down into in depth cost components. For example, the capital expenditure comprises design, construction, installation costs, etc. While, the operational expenditure consists of operation, labor, maintenance costs, etc. Further, Table 2 shows a comprehensive cost component scheme, which the capital expenditure involves $\mathrm{CE}_{1}$ to $\mathrm{CE}_{\mathrm{n}}$, and the operational expenditure contains $\mathrm{OE}_{1}$ to $\mathrm{OE}_{\mathrm{m}}$.

According to [9], the cost component estimate can go through the following steps (see table 2):

1). Determination of formulation variables, such as:

a. $\mathrm{CE}=\mathrm{CE}_{1}+\ldots+\mathrm{CE}_{\mathrm{n}}$ where $\mathrm{CE}_{1}, \ldots \mathrm{CE}_{\mathrm{n}}$ are the cost increases for $\mathrm{CE}$ components respectively

b. $\mathrm{OE}_{\mathrm{t}}=\mathrm{OE}_{1 \mathrm{t}}+\ldots+\mathrm{OE}_{\mathrm{mt}}$ where $\mathrm{OE}_{\mathrm{t}}$ is operational expenditure at the end of the $\mathrm{t}^{\text {th }}$ year. Likewise, $\mathrm{OE}_{1 \mathrm{t}}, \ldots \mathrm{OE}_{\mathrm{mt}}$ are the cost increases for operational expenditure respectively at the end of the tth year

c. $\mathrm{C}_{\mathrm{r}}=$ the real cost due to adding intelligent systems to a conventional community

d. $\mathrm{i}=$ the discount rate (the rate of return that is equivalent to a weighted average cost of capital)

e. $t=$ the year of the cash flow

f. $\quad \mathrm{N}=$ the specified length of economic life of the component of IT in year

g. $[\mathrm{m}, \mathrm{M}]=$ the acceptable and reasonable value range of cost specified by developers, with $\mathrm{m}$ and $\mathrm{M}$ as the thresholds. In practice, those thresholds may rest on owner estimates, planning of budgets, budget realizations in last years, etc.

h. $\mathrm{C}=$ Cost Parameter

2). Formulation of the cost parameter.

As recommended by [9], $\mathrm{OE}_{\mathrm{t}}$ represents the operational expenditure at the end of the $t^{\text {th }}$ year. However, this scale converts to the value at the start of the $1^{\text {st }}$ year with the discount rate $i$ and the economic life length $\mathrm{N}$. In other words, the net present value estimates $\mathrm{OE}_{t}[9][19]$ as follows:

$$
\begin{aligned}
& C r=C E+\sum_{t=1}^{N} \frac{O E_{t}}{(1+i)^{t}} \\
& C= \begin{cases}1 & , 0<C_{r}<m \\
\frac{C_{r}-m}{M-m} & , m \leq C_{r}<M \\
1 & , C_{r} \geq M\end{cases}
\end{aligned}
$$

As appear in the Equation (14), the $\mathrm{C}$ parameter is in the range 0 and 1, which 1 is the highest index of the cost parameter. Thus, based on the Equation (1), the value index equals to the Equation (11) divided by the Equation (14), in which the resulted value is at the three situations. Firstly, V = 1 means that the function is identical to the cost, hence, the added value is normal; secondly, $\mathrm{V}<1$, depicting that the function is less than the cost, which sequentially endangers the business competitive advantage; and thirdly, $\mathrm{V}>1$, where is the best value addressing the highest efficiency of the organizational management. Additionally, because this value comes from the inner power as the built-in IT value, afterward, its term is the intrinsic IT value.

\section{E. IT Value and its Business Environment}

As declared by [6], IT cannot work in an isolation environment, hence, it is appropriate if the IT value blends together with the further values originated from the interaction with the business context. For this reason, the BMC could be a business environment to facilitate a business context of the IT value. The BMC consists of nine building blocks, which are 
customer segments, value propositions, channels, customer relationships, revenue streams, key resources, key activities, key partners, and cost structures [15], [16]. The last four blocks, i.e. key resources, key activities, key partners, and cost structure can make up the inner power of IT resources as the intrinsic value as seen in Figure 2. Accordingly, they are part of those blocks arranging the function parameters represented by the key activities and the cost parameters represented by the cost structure (see the Equation (1)) that each of them is also strengthened by the key partners and the key resources on one hand.

On the other hand, the first five blocks of the BMC, i.e. customer segments, value propositions, channels, customer relationships, and revenue streams act on behalf of the external business environment of the IT value. Those blocks work as business drivers so that the intrinsic IT value may be superior to before due to the reinforcement of those blocks. However, the opposite result can also happen, which the intrinsic IT value lessens because of unhealthy management of the business drivers. In this case, the customer segments are the first driver to develop the business context, whereas the other three blocks (value propositions, channels, and customer relationships) are managerial facilities to reinforce the intrinsic IT value so it can deliver extra other values. Meanwhile, the revenue stream is the front of the business performance in a financial perspective to measure the business. Accordingly, the resulted value due to this consequence is entitled as extrinsic IT value. Therefore, the total value is a multiplication of the intrinsic and the extrinsic values, as figured out in Figure 2.

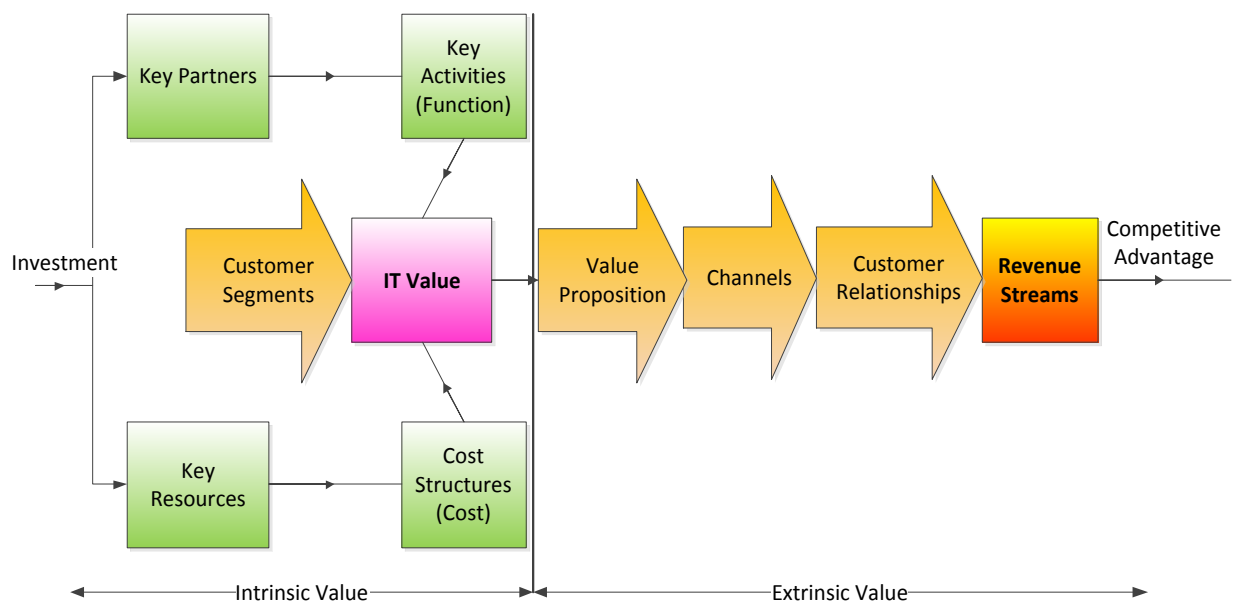

Figure 2. IT value in its business environment

Furthermore, consistent with Figure 2, the total IT value represented by Revenue Streams $(\mathrm{RS})$ is the multiplication of the intrinsic value $(\mathrm{InV})$ and the extrinsic value $(\mathrm{ExV})$ or

$$
R S=\operatorname{In} V^{*} \operatorname{Ex} V
$$

Whereas the InV establishes in the Equation (1), while, the $\mathrm{ExV}$ is as follows:

$$
\text { ExV }=\text { Value proposition }(V P) * \text { Channels }(C h) * \text { Customer relationship }(C R)
$$

In which $\mathrm{VP}, \mathrm{Ch}$, and $\mathrm{CR}$ materialize in respective formulations in this fashion:

$$
V P \rightarrow\left\{\begin{array}{l}
=1, \text { if } V P \text { is the industry standard business suit } \\
0<V P<1, \text { if } V P \text { is less than the industry standard business suit } \\
>1, \text { if } V P \text { is greater than the industry standard business suit }
\end{array}\right.
$$


$C h \rightarrow\left\{\begin{array}{l}=1, \text { if the } C h \text { is available and operated bythe Organization } \\ 0<C h<1, \text { if the } C h \text { is not available } \\ >1, \text { if the Ch is available and operated bythe Organization and } \\ \quad \text { Partners }\end{array}\right.$

$C R \rightarrow\left\{\begin{array}{l}=1, \text { if there are customer or service segments } \\ 0<C R<1, \text { if there are not customer or service segments } \\ >1, \text { if customer or service segments are preferred by top managements }\end{array}\right.$

\section{F. Data Collection}

To clarify and validate both the intrinsic and the extrinsic values, a case study can substantiate this valuation methodology, in which the case study relates to a telco industry as one segment of IT-based industry segments. In essence, the telco industry is representative to be a sample due to the information technology and communication (ICT) industry providers. The selected firm as a sample is Telkom, which has listed on the Indonesia Stock Exchange and the New York Stock Exchange [18]. Annually, Telkom publishes its Annual Report including the Financial Statement, which part of that becomes the data source for this study. In addition, the Annual Reports are not only comprehensive data but also legitimate because the reports have already been audited and agreed by the Annual General Meeting of Shareholders.

\section{G. Data Analysis}

Data analyses follow a sequence of stages as seen in Table 3 below:

Table 3. Research data analysis phases

\begin{tabular}{|l|l|l|}
\hline$\#$ & \multicolumn{1}{|c|}{ Stage } & \multicolumn{1}{|c|}{ Method } \\
\hline 1 & $\begin{array}{l}\text { To analyze a group of functions of Telkom's } \\
\text { operation, split into three: strategic, business, and } \\
\text { financial streams. Each function stream consists of } \\
\text { the fundamental, enhanced, and superior level of } \\
\text { functions. Then the index of each stream and function } \\
\text { parameter are estimated. }\end{array}$ & $\begin{array}{l}\text { Resource-Based View } \\
\text { eTOM (enhanced Telecom } \\
\text { Operation Map) Framework } \\
\text { Telkom Annual Report 2013 } \\
\text { The Equations (2) to (12) }\end{array}$ \\
\hline 2 & $\begin{array}{l}\text { To analyze and assess a group of costs } \\
3\end{array}$ & $\begin{array}{l}\text { Life-Cycle Cost Analysis } \\
\text { (LCCA) } \\
\text { Present Value } \\
\text { The Equations (13) and (14) }\end{array}$ \\
\hline 4 & $\begin{array}{l}\text { To combine the intrinsic IT value with the Business } \\
\text { Model Canvas (BMC) environment. }\end{array}$ & $\begin{array}{l}\text { Value analysis } \\
\text { The Equation (1) }\end{array}$ \\
\hline 5 & $\begin{array}{l}\text { The BMC analysis } \\
\text { Telkom Annual Report 2013 } \\
\text { and Customer Relationship building blocks to result } \\
\text { in the extrinsic IT value }\end{array}$ & $\begin{array}{l}\text { The Equation (16, 17, 18, and } \\
19) \\
\text { Annual Report analysis } \\
\text { The eTOM and LCCA }\end{array}$ \\
\hline 6 & $\begin{array}{l}\text { To assess the total value of IT represented by } \\
\text { Revenue Streams (RS) }\end{array}$ & $\begin{array}{l}\text { The Equation (15) } \\
\text { Value engineering analysis }\end{array}$ \\
\hline 7 & $\begin{array}{l}\text { To compare the RS index with the index of Cost } \\
\text { Parameter (C) to translate the indexes to currency, so } \\
\text { the measurement unit of business performances } \\
\text { should be quantified in percent }\end{array}$ & $\begin{array}{l}\text { Financial statement, i.e.Return } \\
\text { on investment analysis } \\
\text { Value engineering }\end{array}$ \\
\hline
\end{tabular}




\section{The Case Study}

This case study considers that the Telkom's IT services business processes rest on eTOM (enhanced Telecom Operation Map) framework because the eTOM provides telco industries with further comprehensive services that would meet customers' service quality needs [25],[30]. According to the eTOM framework, the IT functions that should conform to an ICT industry are in table A.1 in Appendix.

Table 4. Estimation results of function parameters

\begin{tabular}{|c|c|c|}
\hline Streams & Parameter & Figures \\
\hline \multirow{3}{*}{ Strategy } & $\mathrm{MF}$ & 315 \\
\cline { 2 - 3 } & $\mathrm{SS}$ & 0.82 \\
\cline { 2 - 3 } & $\mathrm{e}_{1}$ & 0.93 \\
\hline \multirow{3}{*}{ Business } & $\mathrm{MF}$ & 602 \\
\cline { 2 - 3 } & $\mathrm{SB}$ & 0.88 \\
\cline { 2 - 3 } & $\mathrm{e}_{2}$ & 0.95 \\
\hline \multirow{3}{*}{ Finance } & $\mathrm{MF}$ & 104 \\
\cline { 2 - 3 } & $\mathrm{SF}$ & 0.89 \\
\cline { 2 - 3 } & $\mathrm{e}_{3}$ & 0.96 \\
\hline
\end{tabular}

According to Table 3 and A.1 (see Appendix), also using the Equations (2) to (12), the estimation of the function parameters results in figures as follows in Table 4. Hence, by the Equation (11), the Function parameter $(\mathrm{F})=0.82$.

While, the cost components organizing the ICT expenditure at Telkom are as seen in Table 5 below, whereas the list of the real CE of Telkom can be seen in Table A.2 in Appendix [18]:

Table 5. Cost components of ICT expenditure (adopted from [18])

\begin{tabular}{|l|l|}
\hline Cost Flow & Cost Components \\
\hline & Procurement cost (Planning, Design, \\
1. Capital Expenditure (CE) & Construction costs) \\
& Installation cost \\
\hline \multirow{3}{*}{ 2. Operational Expenditure (OE) } & 2.1 Operations \\
& 2.2 Maintenance \\
\hline
\end{tabular}

From Table A.2 in Appendix, the total CE in 2013 is at Rp 24,898.0 billion. If assumed that the OE equals to $8 \%^{1}$ of the CE (the OE magnitude in the [18] does not appeared), then the $\mathrm{OE}=\mathrm{Rp} 1,991.84$ billion per year. While the economic life (the year of cash flow) was estimated for 10 years and is also assumed to require the same OE for 10 years to come. Thus, the discount rate is pegged Telkom for 2013 amounted to $13.5 \%$ [18], by using the Equation (13), the outcomes of detailed estimation can result in the following Table 6:

Table 6. Cost components magnitude

\begin{tabular}{|c|c|c|c|c|}
\hline Year (N) & $\begin{array}{c}\text { CE } \\
\text { (Rp billion) }\end{array}$ & $\begin{array}{c}\text { OE } \\
\text { (Rp billion) }\end{array}$ & i & $\begin{array}{c}\mathrm{C}_{\mathrm{r}} \\
\text { (Rp billion) }\end{array}$ \\
\hline 0 & 24,898 & & 1.000000 & $24,898.00$ \\
\hline 1 & & $1,991.84$ & 0.881057 & $1,754.93$ \\
\hline 2 & & $1,991.84$ & 0.776262 & $1,546.19$ \\
\hline 3 & & $1,991.84$ & 0.683931 & $1,362.28$ \\
\hline
\end{tabular}

\footnotetext{
${ }^{1} 8 \%$ is taken based on the example calculation of OE of one project of Telkom
} 


\begin{tabular}{|c|c|c|c|}
\hline 4 & $1,991.84$ & 0.602583 & $1,200.25$ \\
\hline 5 & $1,991.84$ & 0.53091 & $1,057.49$ \\
\hline 6 & $1,991.84$ & 0.467762 & 931.71 \\
\hline 7 & $1,991.84$ & 0.412125 & 820.89 \\
\hline 8 & $1,991.84$ & 0.363106 & 723.25 \\
\hline 9 & $1,991.84$ & 0.319917 & 637.22 \\
\hline 10 & $1,991.84$ & 0.281865 & 561.43 \\
\hline \multicolumn{3}{|c|}{$\mathrm{C}_{\mathrm{r}}(\mathrm{Rp}$ billion $)$} & $35,493.63$ \\
\hline
\end{tabular}

In order to obtain the $\mathrm{C}$ (cost parameter) index, it refers to the Equation (14), which requires $\mathrm{m}$ and $\mathrm{M}$, representing the acceptable and reasonable value range of cost specified by developers, as the thresholds. As stated above, $\mathrm{m}$ and $\mathrm{M}$ refer to the last realization of the $\mathrm{C}_{\mathrm{r}}$. Therefore, $\mathrm{m}$ and $\mathrm{M}$ here come from the value of Telkom's $\mathrm{C}_{\mathrm{r}}$ the smallest and highest during the past ten years, i.e. 2004-2013. The smallest $C_{r}$ is in 2004, i.e. $R p$ 12,574.02 billion, while the largest is in 2013. Thus, $\mathrm{m}=12,574.02 ; \mathrm{M}=35,493.63 ;$ and $\mathrm{C}_{\mathrm{r}}=35,493.63$. Consequently, that $\mathrm{M}=\mathrm{C}_{\mathrm{r}}$, afterward, the value of $\mathrm{C}=1$, according to the Equation (14). For that reason, the intrinsic value $(\mathrm{InV})$, according to the Equation (1), is equivalent to a division of the function parameter $(\mathrm{F})=0.82$ divided by the cost parameter $(\mathrm{C})$; i.e. $\operatorname{InV}=0.82(<1)$, which means that the unnecessary costs happen, which do not contribute to the required functions for the alternative. Therefore, eliminating these unnecessary costs, while maintaining the required performance, quality and safety of the functions, are a necessity.

Meanwhile, to estimate the extrinsic value is based on [18] data. Accordingly, if the VP (value propositions) is a description of bundles of products or services that create values for a specific customer segment, such as value being delivered to the customer (benefit/ cost), customer problem being solved, customer needs being satisfied, and value propositions assigned to the customer segments. Afterward, obtaining from [18] that the bundles of Telkom products and services are in compliance with the product standards, in which a telco industry should be so, such as fixed wireline services, fixed wireless services, cellular services, the internet and data communication services, network services, interconnection services, and ancillary services [18]. As a result, that Telkom has offered standard VPs as a telco industry, thus, the value of VP equals to 1 according to the formula of the Equation (17).

On the other hand, Ch (channels) depicts as how a firm communicates with and reaches its customer segment to deliver a value proposition. The $\mathrm{Ch}$ functions are raising responsiveness among customers about a firm's products and services, helping customers evaluate a firm's value proposition, allowing customers to purchase specific products $\&$ services, delivering a value proposition to customers, and providing post-purchase customer support. Therefore, to measure the Telkom's $\mathrm{Ch}$ is through understanding the type of $\mathrm{Ch}$ and cooperation with the third parties. [18] states that types of Telkom's Ch consist of Plaza Telkom and GraPARI (as walk-in customer service points), Contact Centers (serving products and services through call centers), Partnership Stores (extensions of distribution channels, cooperating with the third parties), Feet on The Street (direct marketing such door-to-door marketing, etc.), Authorized Dealers and Retail Outlets (distribution outlets, cooperating with the third parties), Account Management Teams (those who manage relationships to customer segments), Telkom Solution Houses (special channels for enterprise customers), SME (Small and Medium Enterprises) Centers (communication centers for e-commerce solutions), and Telkom website [18]. According to this clarification, it can estimate the Ch's value by the Equation (18). In addition, from the nine types of channels, two types collaborate with the third parties, namely Partnership Stores, and Authorized Dealers and Retail Outlets. Thus, in this case-study context, the overall channels actually consist of 11 types. Therefore, the value of $\mathrm{Ch}$ is 11 divided by 9 , which equals to 1.22 , see the Equation (11).

Furthermore, the CR (Customer Relationships) describes the types of relationships a firm establishes with specific customer segments. This is necessary to perform in terms of customer 
acquisitions, customer retentions, and boosting sales (upselling), in which their contact can be personal or automated. In this case, Telkom has segmented its customers into four segments: corporate, home, personal, and other segments, whereas the corporate segments provide customers with telecommunications services such as interconnection, leased lines, satellite services, VSAT (Very Small Aperture Terminal), contact centers, broadband accesses, information technology services, data and internet services as companies and institutions. While, the home segment is home consumers, who usually subscribe to fixed wireline services, pay TV, data and internet services. Moreover, the personal segments are individual consumers, who subscribe to mobile cellulars and fixed wireless services including mobile accesses and information technology services, data and internet services. The others are segments dedicated to building management services [18]. Besides that, the management of customer segmentation at Telkom does not complete at the operational level only, but also manage from the top management such as Consumer Service Directorate that manages the consumer business segment, Enterprise and Business Service Directorate that controls the enterprise and smallmedium enterprise business segment, and Wholesale and International Service Directorate that focuses on the wholesale and international business segment. Thus, the value of CR obeys the estimate as follows: each service segment is 1, if all 4 segments exist, the total value is 4 . While, the three special directorates manage the segmentation services, each of which is weighted $0.125^{2}$ so that the total value of 0.375 . In addition, the total value of the segment plus the total value of the directorate will be 4.375 . Thus, the value of CR is 4.375 divided by 4 , which is equal to 1.09, which this estimate is based on the Equation (19).

Therefore, the extrinsic value $(\mathrm{ExV})$ is a multiplication of the VP, the $\mathrm{Ch}$, and the $\mathrm{CR}$ as designated by the Equation (16). Hence, the $\operatorname{ExV}=1.22 * 1.00 * 1.09=1.33$. Furthermore, the overall IT value, represented by RS (Revenue Streams), is the multiplication of the Intrinsic Value (InV) with the ExV as indicated by the Equation (15). Consequently, the RS $=0.82 *$ $1.33=1.09$, which means that if the intrinsic IT value is poor (less than 1 ), it can be magnified by the role of the well managed extrinsic IT value. This case study shows that the final value is greater than $1(1,09)$, indicating the best value addressing the highest efficiency of the organizational management as well. In other words, the final figure indicates that the IT value provides a firm with a worthy performance, if the IT capability optimally works as infrastructures and blends together with the favorable business environment, too.

\section{Discussion and Recommendation}

It is motivating to assess the real IT value within the business organizations because the factors affecting the values are various, consisting of technical, managerial, environmental, and numerous additional aspects. However, the valuation of IT has been accomplished although its results are still covering several weaknesses, which lie on both the intrinsic and extrinsic IT valuations. For example, in the intrinsic IT value, the complications happen in determining functions covered by the IT's role in the organization. The complications arise about whether these functions are created as a direct correlation with the IT procurement or may also refer to ideal standard functions to perform by an IT-related industry, which also follows a particular framework. However, the sum of functions qualitatively manifests by means of the annual report analysis confronted with the eTOM framework. Meanwhile, the eTOM framework is the business process reference because it has become an ideal framework for telco industries. Likewise, in estimating the cost parameter, the complications also come into view because no direct indicators connect each cost to the functions and vice versa. Hence, the cost parameter estimation is by an accumulation approach between the $\mathrm{CE}$ and the $\mathrm{OE}$ components, even though this calculation was still consistent with the Life Cycle Cost Analysis as well.

Additionally, the assessment of function and cost factors considers the internal business environment represented by the four blocks of the BMC, i.e. the key resources, the key activities, the key partners, and the cost structure. For that reason, it needs to assume that the

\footnotetext{
${ }^{2}$ All directorates are eight (8), so that each weighs $1 / 8=0.125$
} 
four blocks have mixed together in the assessment of the functions and the costs automatically. Therefore, the value of each block needs no additional assessments in the intrinsic IT valuation due to its unification into the function and the cost analysis.

Meanwhile, the assessment of the extrinsic IT value has not yet considered the cost components, the capability, and their potentials, in which their assessments are merely based on availability levels. For example, the value of the VP (value proposition) relates to the existence of industry products and services that are suitable for. Similarly, the value of $\mathrm{Ch}$ (channels) connects with the quantity of channels the organization has and does not observe the channels from the quality point of views, such quality of services, operational cost, service effectiveness, etc. Likewise, the identical way happened at the CR (customer relationship), its value rests on the availability of customer or service segments, which is no estimate of its capacity, customer satisfactions, operational costs, etc. Definitely, those factors are parameters of accuracy in determining the extrinsic IT value. However, to measure these parameters take time and need enormous efforts, so if any, those should be included in the estimations or as a correction factor for the value index calculations. Also, the extrinsic IT value has not considered behavior and culture of services, such as friendly services, easiness of access, service level guarantee, etc.

In order to try to assess the business performance parameters such as the return on investment (ROI), the figures of the index is useful to do so. For example, the ROI is equivalent to the (RS - C) divided by the $\mathrm{C}$ index, results in $27 \%$. However, [18] does not present the ROI figures, hence, no clarification concerning the objectivity of the estimated ROI and no comparison with the real ROI. Additionally, at Telkom no CE tracking tools trace contributions of the invested capital to the business performance. Therefore, it is problematic to measure the success or failure of an investment. For that reason, the result of this study is also hard to confront with the realization of business performance as a result of the CE.

Correspondingly, several recommendations to Telkom are as follows:

1) To develop and implement the CE tracking tools to simply measure the invested capital success or failure. This tools should be able to distinguish the business performance whether is an effect of the last spending, the new one or the combination of all.

2) To determine the critical success factors within overall business processes by decomposition of those processes to perform the business criticalities as a success or a failed account. Take them as the critical success factors, in which this way is also useful to decompose the building block of the business process so it is easy to persuade in bringing the organization extrinsic values up.

3) To assess periodically the IT value, especially the IT infrastructures at Telkom do not only as the support infrastructures but also as the business themselves because Telkom is an IToriented service corporation. Sequentially, this valuation helps the management measure the business performance and quickly make the decision.

4) In order to perform the accurate measurements, especially in the extrinsic IT value, it is recommended to provide cost of services to involve in the extrinsic assessments. In turn, it allows the assessor to assess the performance exactly.

\section{Conclusion}

This study tries offering the solution for the IT valuation with the value engineering methodology approach, which stems from two aspects of valuations. The first comes from the inner value of IT resources own, entitled the intrinsic IT value. Furthermore, the second originates from the IT resource business environment, which is an effort to rest the IT on a business context, whereas may enlarge the intrinsic IT value or downgrade it depending upon the business environment potentials. However, IT does not work in an isolated environment, accordingly, this study uses the BMC as the business context. Afterward, this value produces an extrinsic IT value, which combines with the intrinsic IT value. As a result is the overall IT value, which is a multiplication of both the intrinsic and the extrinsic values. 
To examine the valuation methodology, a case study conducted at Telkom confirming that this methodology works considerably, in which the entire IT value is larger than $1(1,09)$, indicating the best value addressing the highest efficiency of the organizational management. In other words, the ultimate figure indicates that the IT value provides a firm with a worthy performance, if the IT capability optimally works as infrastructures and blends together with the favorable business environment, too. However, several waivers of a number of measurement parameters must be there, as this is necessary to facilitate the valuation process in accordance with the developed research methodology. Consequently, this solution looks simple and easy to use on one hand, however, on the other hand, this simplicity ignores some parameters. For example, the valuation of the extrinsic IT value has not yet considered the cost, the quality of services, the accessibility, the capacity, etc. In addition, the valuation is just based on the availability levels of those services.

Accordingly, this study suggests Telkom quite a few recommendations to attempt this methodology to the practical application. And of course, this study needs future works, which should emphasize on the extrinsic value measurement comprehensively. Likewise, this comprehensiveness lies on the estimated parameters within the business environment. In other words, the more complex the business environments the more accurate the valuation.

\section{Reference}

[1]. Abdurrahman, L., Suhardi, Langi, A.Z.R, "Information Technology (IT) Value Model using Variance-Based Structural Equation Modeling: Towards IT Value Engineering", The Second International Conference on Information and Communication Technology, Bandung, pp. 499-504, 28-30 May 2014.

[2]. Abdurrahman, L., Suhardi, Langi, A.Z.R., "Modeling Information Technology (IT) Value: An Ontological Approach towards IT Value Engineering", International Journal of Advances in Software Engineering \& Research Methodology-IJSERM, Vol. 1, No. 2, pp. 34-38, 25 June 2014.

[3]. Abdurrahman, L., Langi, A.Z.R., Suhardi, "Development of Methodologies for Measuring IT Capability in the Information and Communication Industries", International Conference on Information Technology Systems and Innovation (ICITSI) 2014, Bandung-Bali, 24-27 November 2014.

[4]. Bharadwaj, A.S., "A Resource-based Perspective on Information Technology Capability and Firm Performance: an Empirical Investigation", MIS Quarterly, Vol. 24, pp. 169196, 2000.

[5]. Business Model Generation, "What's Your Business Model?" (May 10, 2014) www.businessmodelgeneration.com.

[6]. Cao, G., Wiengarten, F., Humphreys, P., "Towards a Contingency Resource-Based View of IT Business Value", Syst Pract Action Res, pp. 85-106, 2011.

[7]. Datta, A., "Resource Based View of Information Systems: A Critique“, (May 17, 2013) http://ssrn.com/abstract=1029228.

[8]. Gartner, "Gartner Worldwide IT Spending Forecast", (August 2, 2014) www.gartner.com/technology/research/it-spending-forecast/.

[9]. Huang, Z., "Investment Evaluation of Intelligent Residential Communities Using Value Engineering in China", IEEE International Conference on Management and Service Science (MASS), pp. 1-4, 2010.

[10]. Jin-wen, Z., Xiao-ying, Z., "The New Tools of Enterprise's Innovation Management: Value Engineering", Proceeding of International Conference on Information Management, Innovation Management and Industrial Engineering, pp. 507-510, 2009.

[11]. Langi, A.Z.R., "Generic PSV Systems and Their Engine Models", Proceeding of International Conference on System Engineering and Technology, 2012.

[12]. Lee, O.K., Xu,P.,.Kuilboer, P.J.P., Ashrafi, N., "IT Impacts On Performance Of Service Firms Through Operation-Level Dynamic Capability", Journal of Applied Business Research, Vol. 28, pp. 1283-1293, 2012. 
[13]. Liang, T.P., You, J.J., and Liu, C.C., "A resource-based perspective on information technology and firm performance: a meta-analysis", Industrial Management \& Data Systems, Vol. 110, pp. 1138-1158, 2010.

[14]. Lin, B.W., "Information technology capability and value creation: Evidence from Evidence from the US banking industry “, Technology in Society, 29, pp. 93-106, 2007

[15]. Osterwalder, A., "The Business Model Ontology: A Proposition in a Design Science Approach", PhD Dissertation on Université de Lausanne, Switzerland, 2004.

[16]. Panesis, M., "Business Models", (December 6, 2013) www.tmp.ucsb.eduoutreachnvc _ filespdfBusinessModels-20130116.pdf.

[17]. Powell, "Resource-Based View", Encyclopedic Dictionary of Strategic Management, pp. 1-3, 2007.

[18]. PT. Telekomunikasi Indonesia, Tbk., "Creating Global Talents and Opportunities”, 2013 Annual Report, 2014.

[19]. Rahman, S.; Vanier, D.J., "Life cycle cost analysis as a decision support tool for managing municipal infrastructure", CIB 2004 Triennial Congress, Toronto, Ontario, pp. 1-12, May 2-9, 2004.

[20]. Rau S.E., and.Bye, B.S., “Are You Getting Value from Your IT?” Journal of Business Strategy, pp. 16-20, 2003.

[21]. Ravichandran, T. \& Lertwongsatien, C., "Effect of Information Systems Resources and Capabilities on Firm Performance: A Resource-Based Perspective", Journal of Management Information Systems, Vol. 21, pp. 237-276, 2005.

[22]. Schniederjans, M.J., Hamaker, J.L., Schniederjans,A.M., "Information Technology Investment: Decision-Making Methodology”, World Scientific Publishing, 2004.

[23]. Senn, J.A., "Do Managers and IT Professionals View the Business Value of Information Technology Differently?" Proceedings of the 36th Hawaii International Conference on System Sciences (HICSS'03), 2002.

[24]. Sharma, A. and Belokar,R.M., "Achieving Success through Value Engineering: A Case Study", Proceedings of the World Congress on Engineering and Computer Science, 2012.

[25]. Tanovic, A., "Improvement of the eTOM standard through the comparison with ITIL V3 best practices", IEEE 20th Telecommunications forum TELFOR 2012, pp. 36-39, Serbia, Belgrade, November 20-22, 2012.

[26]. Tohidi, H., "Review the benefits of using Value Engineering in Information Technology Project Management”, Procedia Computer Science, Vol. 3, pp. 917-924, 2011.

[27]. Tse, D. C., "A Conceptual Model for Assessing the Value of Information Technology", Thesis on Management Sciences, University of Waterloo, Ontario, Canada, 2006.

[28]. Webb, A (1), "Value Engineering Part 1", Engineering Management Journal, pp. 171$175,1993$.

[29]. Webb, A (2), "Value Engineering Part 2", Engineering Management Journal, pp. 231235, 1993.

[30]. Wong, D., “Adapting e-TOM Model to Improve Multimedia Network Management - A Case Study with a Taiwan Multimedia Service Provider", IEEE Fifth International Conference on Intelligent Information Hiding and Multimedia Signal Processing, pp. 579-582, 2009. 


\section{Appendix}

Table A.1. List of IT functions in Telco industries

Note: The writings that were written off are functions that do not work at Telkom

\begin{tabular}{|c|c|c|}
\hline Groups of IT & & Levels of Functions (eTOM 8) \\
\hline & Fundamental & $\begin{array}{l}\text { 1. Marketing \& Offer Management, 2. Service Development \& Management, } 3 . \\
\text { Resource Development \& Management, } 4 \text {. Supply Chain Development \& } \\
\text { Management. }\end{array}$ \\
\hline & Enhanced & $\begin{array}{l}\text { 5. Market Strategy \& Policy, 6. Product \& Offer Portfolio Planning, 7. Product } \\
\text { \& Offer Capability Delivery, 8. Marketing Capability Delivery, 9. Sales } \\
\text { Development, 10. Product Marketing Communications \& Promotion, 11. } \\
\text { Product \& Offer Development \& Retirement, 12. Service Strategy \& Planning, } \\
\text { 13. Service Capability Delivery, 14. Service Development \& Retirement, 15. } \\
\text { Resource Strategy \& Planning, 16. Resource Capability Delivery, 17. Resource } \\
\text { Development \& Retirement, 18. Supply Chain Strategy \& Planning, 19. Supply } \\
\text { Chain Capability Delivery, 20. Supply Chain Development \& Change } \\
\text { Management }\end{array}$ \\
\hline Strategic & Superior & 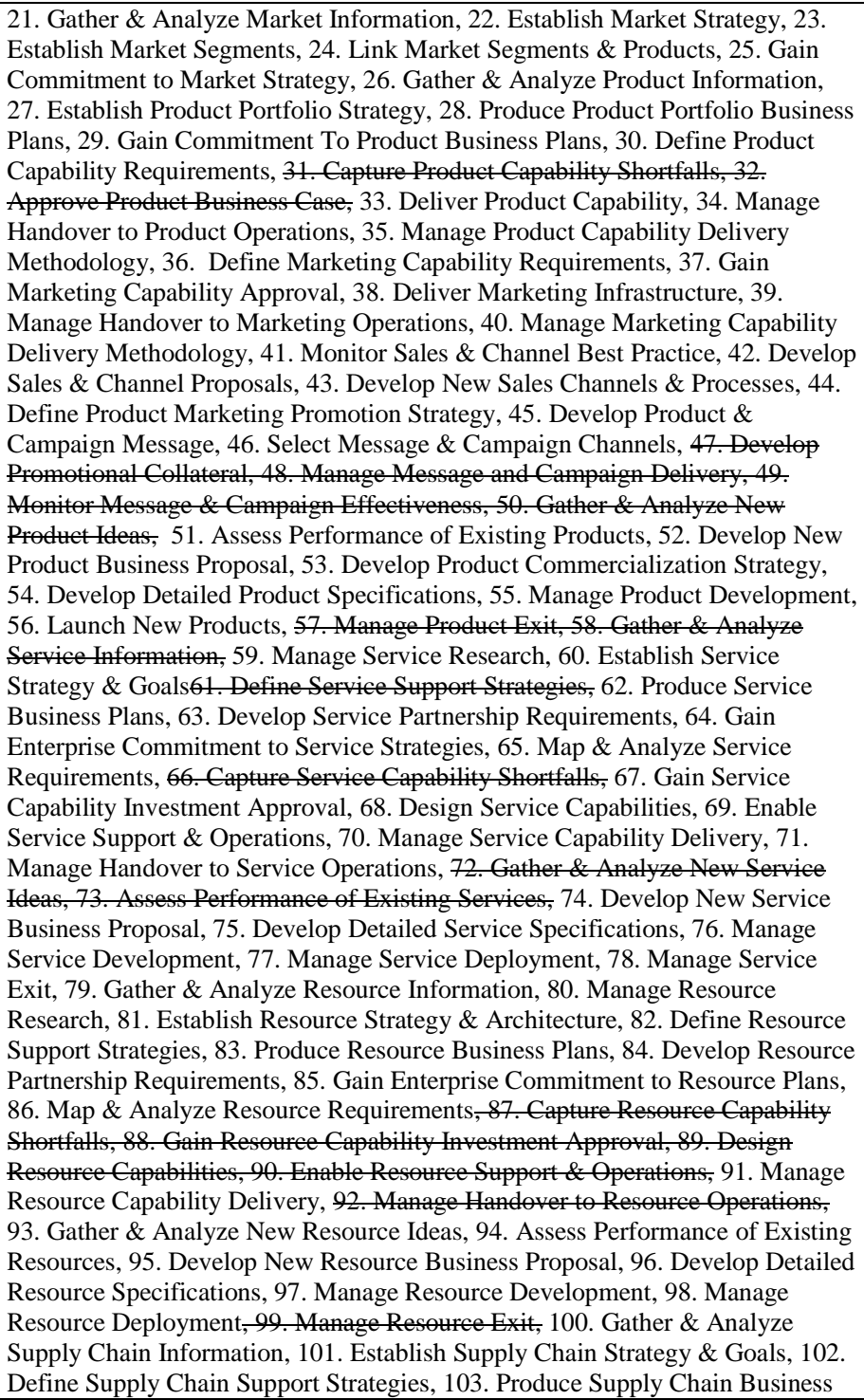 \\
\hline
\end{tabular}




\begin{tabular}{|c|c|c|}
\hline & & $\begin{array}{l}\text { Plans, 104. Gain Enterprise Commitment to Supply Chain Plans, } 105 \text {. } \\
\text { Determine the Seureing Requirements, 106. Determine Potential } \\
\text { Suppliers/Parters, 107. Manage the Tender Process, 108. Gain Tender Decision } \\
\text { Approval, 109. Negotiate Commercial Arrangements, 110. Gain Approval for } \\
\text { Commercial Arrangements, 111. Manage Supplier/Partner Engagement, 112. } \\
\text { Manage Supply Chain Contract Variation, 113. Manage Supplier/Partner } \\
\text { Termination }\end{array}$ \\
\hline \multirow[b]{3}{*}{ Business } & Fundamental & $\begin{array}{l}\text { 1. Customer Relationship Management, 2. Service Management \& Operations, } \\
\text { 3. Resource Management \& Operations, 4. Supplier/Partner Relationship } \\
\text { Management. }\end{array}$ \\
\hline & Enhanced & $\begin{array}{l}\text { 5. CRM Support \& Readiness, 6. Selling, 7. Marketing Fullfilment Response, } 8 . \\
\text { Order Handling, 9. Problem handling, 10. Customer QoS/SLA Management, } 11 . \\
\text { Customer Interface Management, 12. Retention \& Loyalty, 13. Bill payments \& } \\
\text { Receivable Management, 14. Bill Invoice Management, 15. Bill Inquiry } \\
\text { handling, 16. Rating \& Discounting, 17. Manage Billing Events, 18. Billing \& } \\
\text { Collections Management, 19. SM\&O Support \& Readiness, 20. Service } \\
\text { Configuration \& Activation, 21. Service Problem Management, 22. Service } \\
\text { Quality Management, 23. Service Specific Instance Rating, 24. RM\&O Support } \\
\text { \& Readiness, 25. Resource Provisioning, 26. Resource Trouble Management, } \\
\text { 27. Resource Performance Management, 28. Resource Data Collection \& } \\
\text { Distribution, 29. Resource Mediation \& Reporting, 30. Manage Workforce, } 31 . \\
\text { S/PRM Support \& Readiness, 32. S/P Requisition Management, 33. S/P } \\
\text { Problem Reporting \& Management, 34. S/P Performance \& Management, } 35 . \\
\text { S/P Settlements \& Payments Management, 36. S/P Interface Management }\end{array}$ \\
\hline & Superior & 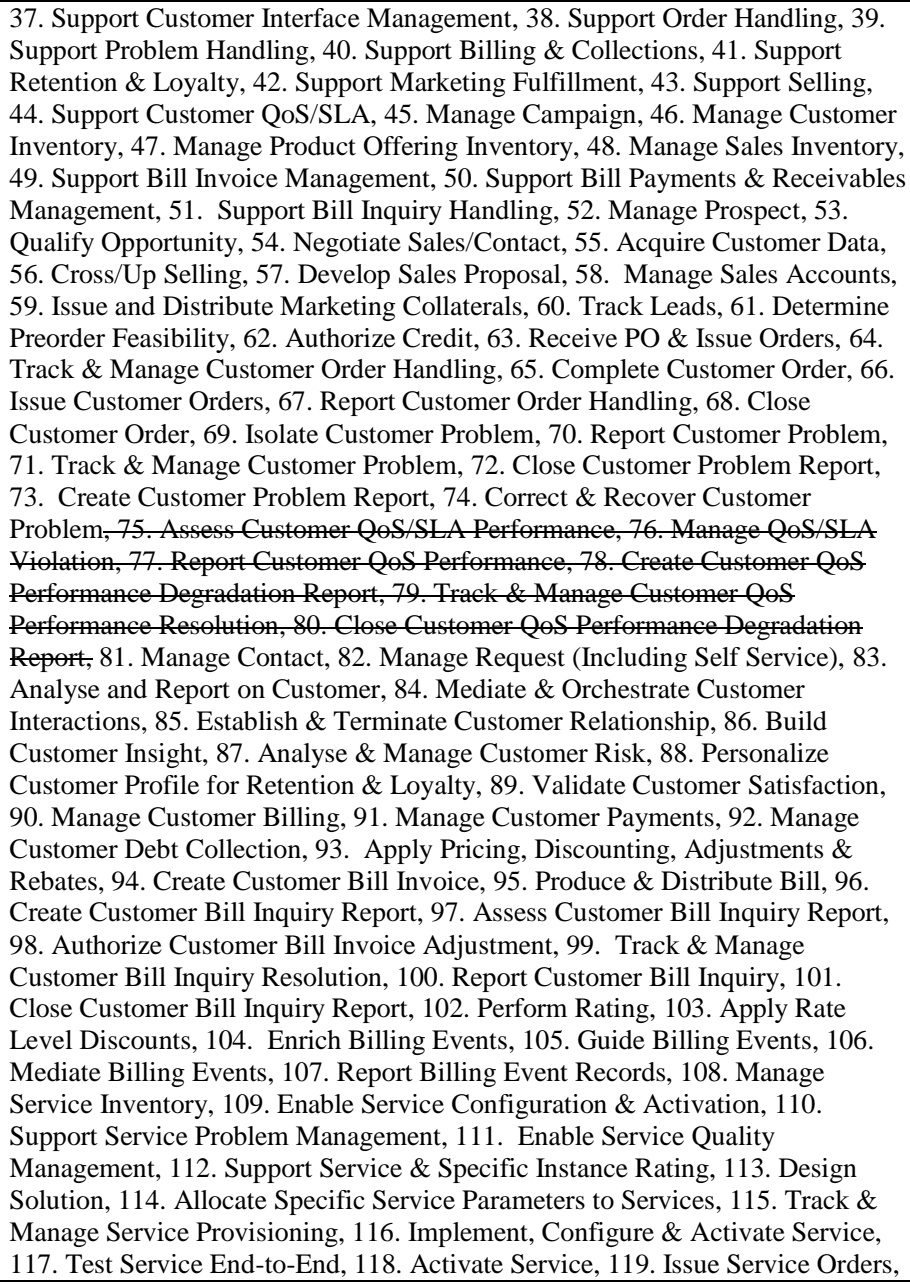 \\
\hline
\end{tabular}




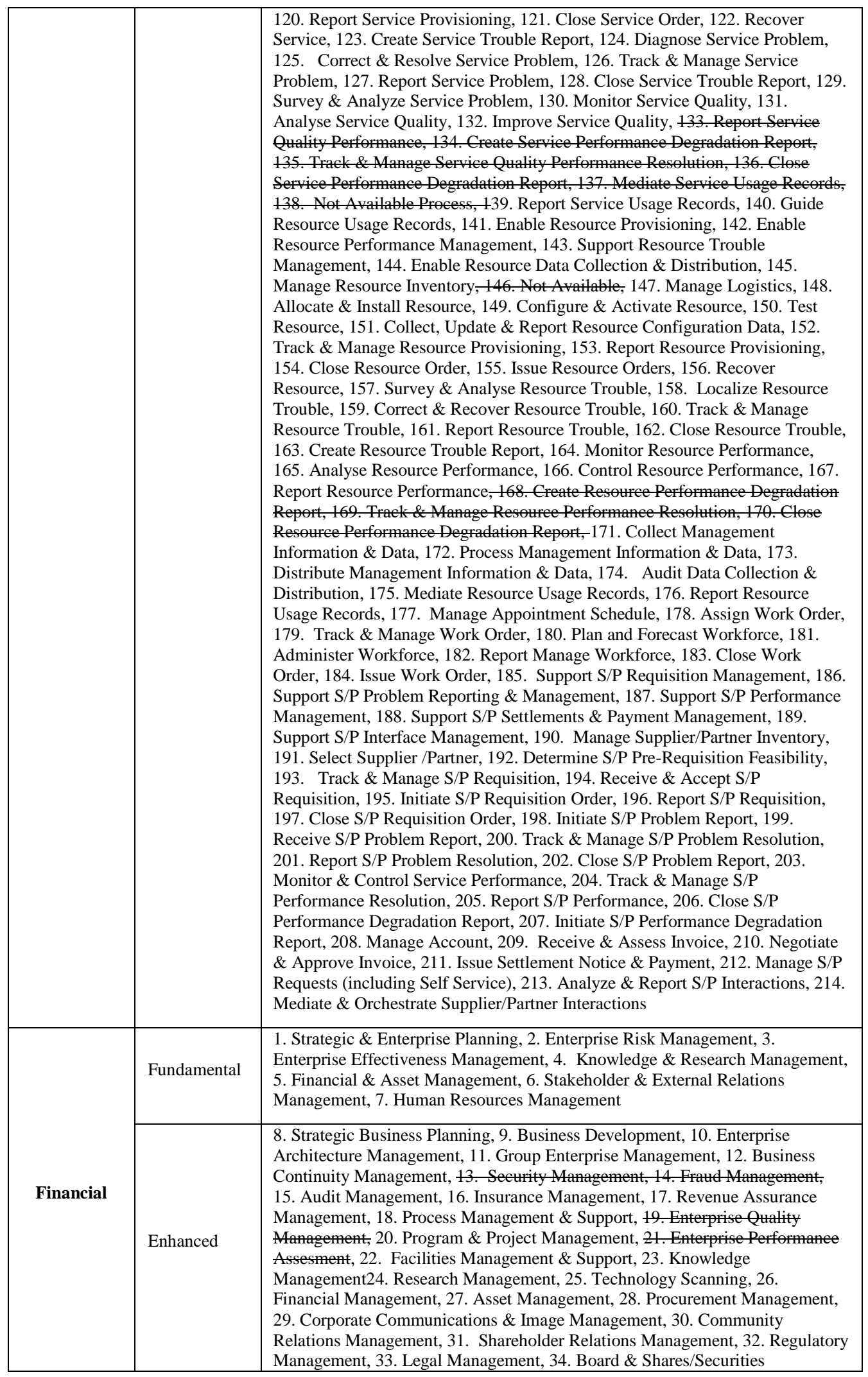




\begin{tabular}{|l|l|}
\hline & $\begin{array}{l}\text { Management, 35. HR Policies \& Practices, 36. Organization Development, } 37 . \\
\text { Workforce Strategy, 38. Workforce development, 39. Employee \& Labor } \\
\text { Relations Management }\end{array}$ \\
\cline { 2 - 3 } & $\begin{array}{l}\text { 40. Manage Revenue Assurance Policy Framework, 41. Manage Revenue } \\
\text { Assurance Operations, 42. Support Revenue Assurance Operations, 43. Warock, } \\
\text { 44. Monitor Revenue Assurance Controls, 45. Create Revenue Assurance } \\
\text { Trouble Report, 46. Assess Revenue Assurance Trouble, 47. Resolve Revenue } \\
\text { Assurance Trouble, 48. Track \& Manage Revenue Assurance Trouble } \\
\text { Resolution, 49. Report Revenue Assurance, 50. Close Revenue Assurance } \\
\text { Trouble Report }\end{array}$ \\
\hline
\end{tabular}

Table A.2. List of Capital Expenditure of Telkom (adopted from [18])

\begin{tabular}{|c|c|c|c|}
\hline & \multicolumn{3}{|c|}{ Yuars Ended December st, } \\
\hline & $\begin{array}{c}2013 \\
\text { (Ro billion) }\end{array}$ & (App bithoril & $\begin{array}{c}20 h \\
\text { con bition }\end{array}$ \\
\hline \multicolumn{4}{|l|}{ Telkom (partant eampony) } \\
\hline Aroodhend aervice & 32855 & 16620 & $18 \pi 50$ \\
\hline Nutwonk service & 14744 & 200000 & 19790 \\
\hline Ostiming legecy & tân 0 & $\infty 60$ & t5e0 \\
\hline Subeort & $x \in 2\}$ & 2320 & 192.0 \\
\hline Subtotal for Tolkom. & 5.3130 & $4,040.0$ & $4,202.0$ \\
\hline \multicolumn{4}{|l|}{ Subsieiarios: } \\
\hline Teikambel & 75.6620 & 10.6560 & 8.4720 \\
\hline Others & 3.9250 & 25700 & 19290 \\
\hline Subtotal for subsidienies & 10.585 .0 & 13,2320 & 10,4010 \\
\hline Toted for Teiliam Grouss & $24,2900.0$ & 10,2720 & 14.0050 \\
\hline
\end{tabular}

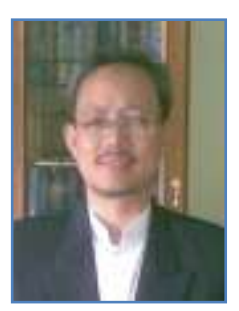

Lukman Abdurrahman is a doctorate student at the School of Electrical Engineering and Informatics, Institute of Technology Bandung (ITB), Bandung Indonesia. He received Bachelor of Engineering Physics from ITB in 1988, Master of Information Systems in 1999 from Claremont Graduate University, Claremont, California, USA. He holds Certification in Risk Management Assurance (CRMA) of The Institute of Internal Auditors (IIA). $\mathrm{He}$ has worked for PT. Telekomunikasi Indonesia, Tbk., which has been seconded as a lecturer at Telkom University since the end of 2012.

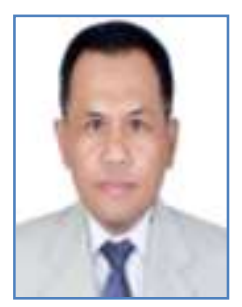

Suhardi, Associate Professor at the School of Electrical Engineering and Informatics (SEEI), Institute of Technology Bandung (ITB), Indonesia. He received Bachelor of Electrical Engineering, ITB, in 1988, Doctor of Engineering from Technical University of Berlin, Germany, in Telecommunication Engineering in 1997. He also holds Master of Management from Parahyangan Chatolic University, Indonesia, in 2012. He is head of Information Network and Systems Research Group (INSRG), SEEI, ITB. His research interests are IT value \& risk, service systems engineering, information \& social networks, information governance \& management, and Internet society \& law.

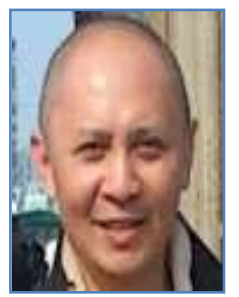

Armein Z.R. Langi, Professor at the School of Electrical Engineering and Informatics (SEEI), Institute of Technology Bandung (ITB), Bandung Indonesia. He received Bachelor of Electrical Engineering, ITB. MSc and $\mathrm{PhD}$ in Electrical Engineering from the University of Manitoba, Canada. His expertise is in Digital Signal Processing, Multimedia Compression, Multimedia Communication System, and DSP System Engineering. He is IEEE member. 